\title{
A decentralized, patient-centered approach to diabetes disease management in the primary care setting
}

\author{
Michael Toscani \\ HealthAnswers Inc. \\ John P. O'Connor \\ Thomas Jefferson University \\ David B. Nash \\ Thomas Jefferson University
}

Follow this and additional works at: https://jdc.jefferson.edu/healthpolicyfaculty

Part of the Health Services Research Commons

Let us know how access to this document benefits you

\section{Recommended Citation}

Toscani, Michael; O'Connor, John P.; and Nash, David B., "A decentralized, patient-centered approach to diabetes disease management in the primary care setting" (2001). College of Population Health Faculty Papers. Paper 8.

https://jdc.jefferson.edu/healthpolicyfaculty/8

This Article is brought to you for free and open access by the Jefferson Digital Commons. The Jefferson Digital Commons is a service of Thomas Jefferson University's Center for Teaching and Learning (CTL). The Commons is a showcase for Jefferson books and journals, peer-reviewed scholarly publications, unique historical collections from the University archives, and teaching tools. The Jefferson Digital Commons allows researchers and interested readers anywhere in the world to learn about and keep up to date with Jefferson scholarship. This article has been accepted for inclusion in College of Population Health Faculty Papers by an authorized administrator of the Jefferson Digital Commons. For more information, please contact: JeffersonDigitalCommons@jefferson.edu. 


\title{
A Decentralized, Patient-Centered Approach to Diabetes Disease Management in the Primary Care Setting
}

\author{
MICHAEL TOSCANI, Pharm.D., ${ }^{1}$ JOHN P. O'CONNOR, Ph.D., ${ }^{2}$ \\ and DAVID B. NASH, M.D., M.B.A. ${ }^{2}$
}

\begin{abstract}
Although many disease management programs have been developed for diabetes, no single design has proved best for all providers and patient populations. Cost effectiveness is especially relevant to diabetes programs because significant costs of the disease may come from complications that occur later in life, while the costs of the program are incurred immediately. For this reason, diabetes disease management programs with positive outcomes and low implementation costs are of particular importance. We report here on the outcomes of a pilot test of the Steps to Health ${ }^{\mathrm{TM}}$ program developed by Abbott Laboratories. The Steps to Health $^{\mathrm{TM}}$ program was designed to improve patients' compliance for their diabetes care by increasing their knowledge and understanding of diabetes. The pilot test format utilized a decentralized approach to implement the Steps to Health ${ }^{\mathrm{TM}}$ program and included assessments of clinical, process, and quality-of-life outcomes. The study used a prospective, observational, pre-post design. Patients were assessed at enrollment and at 6 months. The primary clinical outcome was glycemic control, as measured by HbA1c. For the 70 patients (18\% of enrollment) with complete baseline and endpoint data, mean decrease in HbA1c was $1.7 \%(p<$ 0.0001). Clinical process measures of preventive diabetes care showed minor changes in rates between the pre- and postenrollment periods. There was also significant improvement in patient satisfaction regarding their knowledge of diabetes, overall ability to take care of diabetes, and helpfulness of the information received. These results suggest that a diabetes disease management program that is relatively inexpensive and easy to implement, centered on patient education in self-management, can achieve clinically significant improvements in glycemic control for a specific period of time (6 months) and result in a high level of patient satisfaction.
\end{abstract}

\section{INTRODUCTION}

D IABETES MELLITUS is among the most prevalent chronic diseases in the United States, afflicting $5.9 \%$ of the population. ${ }^{1}$ Diabetes and its complications have a dramatic impact on health, quality of life, and healthcare expendi- tures. The economic effects of excess morbidity and lost productivity are significant. As the U.S. population ages, the disease will afflict increasing numbers of the 10.3 million diagnosed and the additional 5.4 million undiagnosed $(1998)^{1}$ at ages when the toll is most severe.

The American Diabetes Association has re-

${ }^{1}$ HealthAnswers, Inc., Pennington, New Jersey.

${ }^{2}$ Office of Health Policy, Thomas Jefferson University, Philadelphia, Pennsylvania. 
cently published detailed standards of preventive care for patients with diabetes. ${ }^{2}$ These guidelines are evidence-based, including results of randomized, controlled trials, and are frequently updated. Despite the availability of consensus-based best practices, it is well documented that the nationwide standard of practice falls short of these goals. ${ }^{3}$ This is the result of many factors, including the insidious nature of the disease, the time required of healthcare providers in education and follow-up that would induce and maintain positive changes in patient and physician behavior, and the infrastructure and resources required for proactive, population-based management of the disease.

One way to address the complexity of managing diabetes in the primary care setting is to supplement physician efforts through disease management programs. There is a multiplicity of such programs for diabetes; no single design has proven best for all providers and patient populations. Sponsors of such plans include payors, employers, and healthcare suppliers and providers. For all sponsors, a key issue is the cost effectiveness of disease management interventions. This is especially relevant to diabetes because significant costs of the disease come from complications that may occur later in life, while the costs of a disease management program are incurred immediately. Thus, estimating and comparing the costs and benefits of disease management is especially difficult in diabetes, and this has impeded a widespread acceptance of a variety of different programs. For this reason, diabetes disease management programs with noteworthy outcomes and low implementation costs are of particular importance.

We report here on the outcomes of a pilot test of such a program, the Steps to Health ${ }^{\mathrm{TM}}$ program developed by Abbott Laboratories. The Steps to Health ${ }^{\mathrm{TM}}$ program focused on improving overall health status, quality of life, and quality of care. It was designed to improve patients' compliance for their diabetes care by increasing their knowledge and understanding of diabetes. This would assist in their ability to make informed choices regarding their care. The link between lack of glycemic control and onset of diabetic complications has been documented. ${ }^{4}$ For this reason, the program design is centered primarily on improving $\mathrm{HbA} 1 \mathrm{clev}$ els by increasing patient education and frequency of patient self monitoring of glucose levels. Patient education also encompassed the ADA-recommended guidelines regarding periodic retinal exams, foot exams, and laboratory tests of lipid levels, creatinine, and albumin. The program was based on training patients to plan their diabetes care using a detailed daily organizer, the Steps to Health ${ }^{\mathrm{TM}}$ Diabetes Planner. A diabetes educator was used to review the planner by conducting 1-hour training seminars designed for either one-to-one or group sessions. In addition, patients were given a blood glucose meter (Precision Q.I.D. ${ }^{\circledR}$ ) with access to 24-hour phone training and support. The patients were then sent quarterly reminder cards regarding periodic physician visits and health tips. Provider education was made available with the program, although the primary focus was on patient education and the care that patients should be receiving from their physician. Provider education included the following three diabetes monographs:

1. See Diabetes through the Patient's Eyes

2. Type 2 Diabetes: The Silent Epidemic

3. HbA1c: The Key to Glycemic Control

\section{MATERIALS AND METHODS}

A pilot study of the program was sponsored by Abbott Laboratories and Columbia/HCA in collaboration with physicians in an affiliated diabetes clinic as well as primary care physicians in practice in the Nashville area. The sponsors wanted a pilot test format that could be completed within 2 years and would include clinical, process, and quality-of-life outcomes. Patient enrollment required more time than anticipated; as a result, patients were followed for 6 months instead of 1 year as originally planned.

Economic outcomes were not included in the evaluation because of the short time frame and limitations associated with collecting health services utilization for the patient population in the study.

The study utilized a decentralized approach for the implementation of the Steps to Health ${ }^{\mathrm{TM}}$ 
program. This included a patient-focused model to emphasize education and to provide tools for compliance. The decentralized approach was designed for voluntary participation by physicians and patients. It did not require physicians to standardize patient care regarding therapy guidelines treatments, appointments, or procedures. The study did not explicitly attempt to change physician behavior, and their participation consisted simply of allowing the study coordinator to review charts of those patients enrolled in the program. The study used a prospective, observational, prepost design. Patients were assessed at enrollment and at 6 months. Analysis of each outcome was performed on an intent-to-treat basis, including all enrolled patients for whom baseline and endpoint data were available.

The primary clinical outcome was glycemic control, as measured by a change in HbA1c. Stratified analysis was necessary for characterization of change in $\mathrm{HbA} 1 \mathrm{c}$ because the enrolled population varied significantly with respect to level of control at baseline. Absolute change in $\mathrm{HbA} 1 \mathrm{c}$ and even a percentage reduction are harder to achieve for patients with lower baseline levels and do not have the same clinical significance as for patients with high levels. Therefore, patients were stratified into four groups based on $\mathrm{HbA1c}$ at enrollment: in control $(<7)$, borderline $(7-8)$, moderate
(8.1-10), and severe $(>10)$. These strata were analyzed individually.

The following clinical process measures were also assessed by noting whether tests were performed in the 6-month periods pre- and postenrollment: retinal exam, foot exam, HbA1c, urinalysis, glucose, albumin, creatinine, and lipids.

Patient health-related quality of life and satisfaction with the diabetes program were assessed using the Medical Outcomes Study 12 Item Short Form $\left(\mathrm{SF}-12^{\circledR}\right)$ and a customized satisfaction questionnaire administered at enrollment and at 6 months. Provider satisfaction was also assessed in a customized questionnaire administered at the end of the study.

Data collection was done by patient survey and chart abstraction. Charts were reviewed individually, and the data for the 12-month study period were entered onto a case report form. These data were then entered in a database for statistical analysis using SAS (version 6.12). Because the program was not coordinated with the physicians' scheduling of individual patients, a range of 6 months plus or minus 1 month was used in interpreting the pre- and postenrollment data. Patients were enrolled on a rolling basis, beginning in January 1998, with the final patient completing the pilot study in September 1999.

\begin{tabular}{|c|c|}
\hline Demographic & Percentage \\
\hline \multirow[t]{2}{*}{ Age (years) } & $52.3($ mean $)$ \\
\hline & 43.7 (25\%ile) $\quad 60.6$ (75\%ile) \\
\hline Gender & $43.4 \%$ male $/ 56.6 \%$ female \\
\hline \multicolumn{2}{|l|}{ Ethnicity } \\
\hline Caucasian & $81.5 \%$ \\
\hline African-American & $17.8 \%$ \\
\hline Other & $0.7 \%$ \\
\hline \multicolumn{2}{|l|}{ Education } \\
\hline Less than high school (HS) & $19.7 \%$ \\
\hline HS & $29.5 \%$ \\
\hline Post HS & $30.1 \%$ \\
\hline College graduate & $20.8 \%$ \\
\hline \multicolumn{2}{|l|}{ General health } \\
\hline Smoker & $22.2 \%$ \\
\hline BMI & 34.5 (mean) \\
\hline SF12 (PCS) & 40.6 (U.S. mean 50.0) \\
\hline SF12 (MCS) & 39.6 (U.S. mean 50.0) \\
\hline
\end{tabular}




\begin{tabular}{|c|c|}
\hline \multicolumn{2}{|c|}{ Diabetes status $(\mathrm{n}=379)$} \\
\hline Time since diagnosis & Median $<1$ year, $75 \%$ ile $=5$ years \\
\hline Type I & $8.8 \%$ \\
\hline Type II & $91.2 \%$ \\
\hline $\begin{array}{l}\mathrm{HbA} 1 \mathrm{c} \text { at enrollment } \\
\quad(n=193)\end{array}$ & 8.7 (mean) \\
\hline \multicolumn{2}{|l|}{ Stratified groups $(n=193)$} \\
\hline In control $<7.0$ & $21.8 \%$ \\
\hline Borderline $\quad 7.0-8.0$ & $21.7 \%$ \\
\hline Moderate & $28.0 \%$ \\
\hline Severe & $28.5 \%$ \\
\hline
\end{tabular}

\section{RESULTS}

A total of 379 patients, representing 114 different physicians, were enrolled in the program. Demographics, general health status, and diabetic status are shown in Tables 1 and 2. The patient population was predominantly middle aged, lower to middle socioeconomic status, overweight, and below U.S. means in health status as measured by the SF-12.

The study outcomes are shown in Tables 3-5 and Figure 1. Table 3 and Figure 1 show the change in $\mathrm{HbA} 1 \mathrm{c}$ for those patients for whom both baseline and 6-month data were available. The larger population shown in Table 2 had a similar distribution of baseline values, but only 70 (18\% of enrollment) had 6 -month data, as shown in Table 3. Overall, these patients showed a mean decline in $\mathrm{HbA} 1 \mathrm{c}$ of $1.7 \%$, with $25 \%$ of patients showing a decline of $3 \%$ or more. This improvement in HbA1c is statistically significant $(p<0.0001)$.

Clinical process measures of preventive diabetes care (Table 4) showed minor improvement in rates between the 6-month pre- and postenrollment periods; however, because some preventive measures (e.g., eye exams) require only annual assessment, results must be interpreted carefully.

Health-related quality of life was measured using the SF-12, administered at enrollment and at 6 months. Baseline and endpoint data were available for 37 patients $(10 \%$ of the enrolled population). For these patients, the physical component score declined slightly (39.5 versus $40.5, p=0.20$ ), while the mental component improved moderately (39.4 versus 36.5 , $p=0.04)$.

Patient satisfaction was measured on a fivepoint Likert scale. Survey questions assessed patients' satisfaction with their current diabetes care at enrollment and at 6 months. Table 5 shows significant increase in satisfaction among the 115 patients (38\% of enrollment) surveyed. In particular, patients' satisfaction with their knowledge of diabetes $(p<0.001)$, their overall ability to take care of their diabetes $(p<0.01)$, and how helpful they thought the information was that they had received for taking care of their diabetes $(p<0.001)$ all showed significant improvements.

Provider satisfaction was assessed at the end

\begin{tabular}{|c|c|c|c|}
\hline \multicolumn{2}{|c|}{ Stratified groups } & \multirow{2}{*}{$\frac{\text { At baseline }}{18.6 \%}$} & \multirow{2}{*}{$\frac{\text { At } 6 \text { months }}{54.3 \%}$} \\
\hline In control & $<7.0$ & & \\
\hline Borderline & $7.0-8.0$ & $24.3 \%$ & $28.6 \%$ \\
\hline Moderate & $8.1-10.0$ & $35.7 \%$ & $15.7 \%$ \\
\hline Severe & $>10.0$ & $21.4 \%$ & $1.4 \%$ \\
\hline \multicolumn{4}{|c|}{$\begin{array}{l}n=70 . \\
61 \% \text { improved at least one class; } 29 \% \text { stayed in the same } \\
\text { class; } 10 \% \text { moved to a worse class. }\end{array}$} \\
\hline
\end{tabular}




\begin{tabular}{|lcc|}
\hline \multicolumn{3}{|c|}{$\begin{array}{c}\text { Table 4. } \\
\text { Comprenensive Diabetes Care }\end{array}$} \\
\hline & \multicolumn{2}{c|}{ Percentage of patients with annual test/exam } \\
\cline { 2 - 3 } & 6-month preenroll & 6-month postenroll \\
\hline Retinal exam & 21.1 & 26.3 \\
Foot exam & 44.5 & 48.2 \\
HbA1c & 63.4 & 63.7 \\
Lipid profile & 50.5 & 45.3 \\
Creatinine & 46.3 & 42.6 \\
Albumin & 25.0 & 21.6 \\
Glucose & 67.6 & 68.7 \\
Urinalysis & 39.2 & 31.1 \\
\hline \multicolumn{2}{c}{$n$} \\
\hline
\end{tabular}

of the study through an anonymous questionnaire. Unfortunately, the response rate was only $6 \%$, and because of anonymity, it could not be determined what percent of patients were represented by these responders. Therefore, the physician responses are not presented in detail here, although all responses received were strongly positive.

Surveys were administered at enrollment to all 379 patients, and follow-up at 6 months was done by mail, with a $30 \%$ response rate. Thus, changes in patient satisfaction could be assessed in a larger proportion of patients than the $18 \%$ with complete clinical data. The patients were dispersed among over 100 providers, which made chart review and interpretation a lengthy process, requiring an average of approximately 1 hour per chart. Charts in different practices varied widely in completeness, especially with respect to dates of service provided and legibility. The paperbased chart system also lacks a uniform data

Table 5. Patient Satisfaction

\begin{tabular}{|c|c|c|c|}
\hline & & Baseline & 6 months \\
\hline $\begin{array}{l}\text { 1. In the last } 3 \text { months, how satisfied have you been with your } \\
\text { knowledge of your diabetes? }\end{array}$ & $\%$ "very satisfied" & 32.3 & 63.5 \\
\hline $\begin{array}{l}\text { 2. In the last } 3 \text { months, how satisfied have you been with your } \\
\text { overall ability to take care of your diabetes? }\end{array}$ & \% "very satisfied" & 35.6 & 59.4 \\
\hline $\begin{array}{l}\text { 3. In the last } 3 \text { months, how often have you been able to control } \\
\text { your blood sugar levels? }\end{array}$ & $\%$ "frequently" & 48.6 & 62.9 \\
\hline $\begin{array}{l}\text { 4. In the last } 3 \text { months, how often have your blood sugar levels } \\
\text { been high? }\end{array}$ & \% "frequently" & 34.8 & 14.5 \\
\hline $\begin{array}{l}\text { 5. How satisfied are you with the medications that you take for } \\
\text { your diabetes? }\end{array}$ & \% "very satisfied" & 46.7 & 47.6 \\
\hline $\begin{array}{l}\text { 6. How satisfied are you with the amount of information given to } \\
\text { you by your health plan about taking care of your diabetes? }\end{array}$ & $\%$ "very satisfied" & 42.7 & 54.5 \\
\hline $\begin{array}{l}\text { 7. How helpful is the amount of information given to you by your } \\
\text { health plan about taking care of your diabetes? }\end{array}$ & \% "very helpful" & 43.4 & 54.9 \\
\hline $\begin{array}{l}\text { 8. Overall, how satisfied are you with your health plan's diabetes } \\
\text { program? }\end{array}$ & \% "very satisfied" & 41.5 & 54.7 \\
\hline $\begin{array}{l}\text { 9. How satisfied are you with the way the staff in the diabetes } \\
\text { program treat you? }\end{array}$ & \% "very satisfied" & 57.9 & 68.2 \\
\hline $\begin{array}{l}\text { 10. How satisfied are you with the number of times that the } \\
\text { diabetes program staff have talked to you? }\end{array}$ & \% "very satisfied" & 55.3 & 54.4 \\
\hline $\begin{array}{l}\text { 11. How likely are you to recommend your health plan's diabetes } \\
\text { program to someone else who has your kind of diabetes? }\end{array}$ & \% "very likely" & 61.3 & 64.5 \\
\hline
\end{tabular}




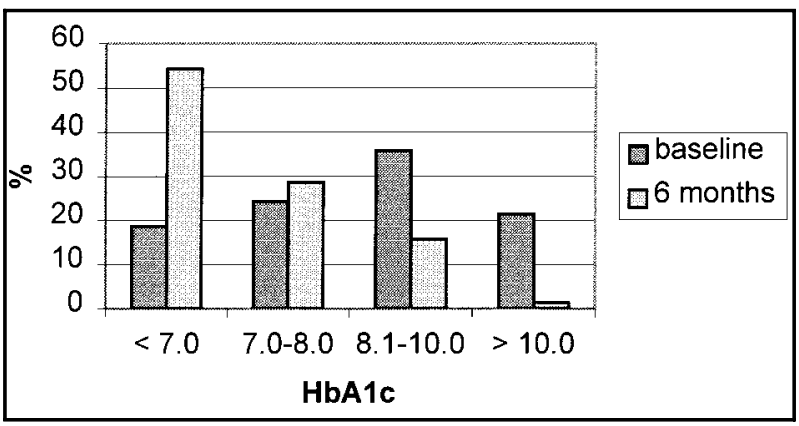

FIG. 1. Glycemic control: pre- versus post-enrollment. $n=70$.

format. Because the patient appointment schedule was not coordinated with enrollment, judgment was required in interpreting the timing of the various events in the chart in relation to the pre- versus poststudy design.

\section{DISCUSSION}

\section{Pilot study}

The most notable positive outcomes of the pilot evaluation are the measured decrease in $\mathrm{HbA} 1 \mathrm{c}$ and the high level of patient satisfaction postenrollment in the Steps to Health ${ }^{\mathrm{TM}}$ program. The evaluable patient population experienced a $1.7 \%$ reduction in their $\mathrm{HbA} 1 \mathrm{c}$ level. The high level of patient satisfaction is another indicator of success regarding the program's ability to increase patient knowledge and understanding of their diabetes. It is difficult to directly compare the effectiveness of different diabetes disease management (DDM) programs because outcomes are influenced by differences in the respective populations: proportion of type I/type II patients, age, years since diagnosis, health status, lifestyle, and socioeconomic and educational status. Nevertheless, published outcomes studies give an indication of the range of results that have been achieved. While not a disease management program, the Diabetes Control and Complications Trial (DCCT) provides a useful reference point for type I glycemic control, achieving a mean reduction in $\mathrm{HbA} 1 \mathrm{c}$ of approximately $1.9 \%$ at 6 months in an intensively managed population. ${ }^{4}$ Testa and Simonson. ${ }^{5}$ report on results from a randomized, double-blind study of glipizide versus placebo in a type 2 population with similar demographics to the current study. HbA1c declined $1 \%$ over the 15 -week study. Aubert et al. ${ }^{6}$ report on effectiveness of nurse case management in a clinically similar population in a group model HMO. O'Connor et al., ${ }^{7} \mathrm{McC}$ Colloch et al., ${ }^{8}$ and Sperl-Hillen et al. ${ }^{9}$ report on population-based approaches to disease management in the primary care setting. Table 6 summarizes the results of these studies with respect to glycemic control.

It is generally accepted that consistent patient self-management is the essential core of diabetes care. Without patient commitment to actively control glycemic levels and necessary lifestyle changes, physicians must focus on prevention and monitoring for complications so as to diagnose them as soon as possible. Thus, the Steps to Health ${ }^{\mathrm{TM}}$ program addresses the most essential element of diabetes care. In a followup survey, $68 \%$ of the patients who were using the Steps to Health ${ }^{\mathrm{TM}}$ Diabetes Planner at the

Table 6. Achievement of Glycemic Control in Controlled Studies

\begin{tabular}{|c|c|c|c|c|c|}
\hline \multirow[b]{2}{*}{ Study } & \multirow[b]{2}{*}{ Duration } & \multirow[b]{2}{*}{$N^{1}$} & \multicolumn{3}{|c|}{ Mean $\mathrm{HbA1c}(\%)$} \\
\hline & & & Baseline & End & $\Delta$ \\
\hline DCCT, 1983-93, clinical trial (intensive management IDDM) & 6.5 years & 348 & 8.8 & $6.9^{2}$ & $1.9^{2}$ \\
\hline Testa et al., 1998, clinical trial (glipizide in type 2 DM) & 15 weeks & 377 & 8.5 & 7.5 & 1.0 \\
\hline Aubert et al., 1998, nurse case management (Type 2) & 12 months & 71 & 9.0 & 7.3 & 1.7 \\
\hline O'Connor et al., 1996, CQI at HMO primary care clinics & 12 months & 122 & 8.9 & 8.4 & 0.5 \\
\hline McCulloch et al., 1998, population-based management in HMO & 4 years & 15,000 & $n / a^{3}$ & 7.6 & $\mathrm{n} / \mathrm{a}$ \\
\hline Sperl-Hillen et al., 1999, DDM in large health system & 12 months & 5,940 & 7.86 & 7.47 & 0.39 \\
\hline
\end{tabular}


end of the study were still using it 6 months later.

This program targeted physician behavior indirectly by offering physicians educational monographs and attempting to increase patient awareness of their diabetes care. As a result, the intervention had a low impact on physician behavior regarding the performance of ADArecommended routine diabetic tests/evaluations and providing patient education in various aspects of self-care. Although the changes were low, the overall rates were in line with nationwide data collected by the National Committee for Quality Assurance (NCQA). The Steps to Health ${ }^{\mathrm{TM}}$ program is designed to maximize the benefits of patient self-management by focusing on patient education and compliance. For the long term, the program relies on the Steps to Health ${ }^{\mathrm{TM}}$ Diabetes Planner, the glucose meter provided, and quarterly reminder cards. Thus, excluding the costs of program evaluation, the program is less resource intensive than DDM programs that have ongoing patient meetings and events, diabetes educators available on an ongoing basis, and formal provider education. The relative cost of the program is correspondingly low if the effectiveness is measured, for example, by cost per 1-point reduction in $\mathrm{HbA} 1 \mathrm{c}$.

\section{Implications}

According to Zitter, ${ }^{10}$ the evolution of disease management programs will follow four stages: (1) programs that focus only on specific care elements in individual patients; (2) programs that target entire populations for high-impact interventions; (3) integrated care for entire populations; and (4) proactive health management of entire populations. However, experience has shown that these stages, rather than reflecting the inevitable direction of evolution, may simply represent points on a cost continuum. The program documented here contains elements from type 1, i.e., primary focus on glycemic control, and type 2 , in attempting to manage an entire enrolled population rather than only identifying high-utilization individuals within that population. To the degree that it was able to accomplish these objectives at a relatively modest cost per patient, the program demonstrates that it is a viable alternative on the cost/benefit continuum.

\section{Outcomes measurement}

The experience gained in this program also contains significant implications for the design and administration of a disease management program, specifically with respect to outcomes measurement, outcomes reporting, and data collection.

There are three clear implications for outcomes measurement. First, there must be a specified frequency of evaluation (e.g., every 6 months in the DDM program considered here), and every patient must be assessed in every time period. Although this may require significant additional effort and cost, program effectiveness cannot be measured without reasonably complete data for all enrolled patients. Second, the outcomes measured are determined by the program goals. According to the ECHO model of outcomes measurement, ${ }^{11}$ these can be categorized as clinical, humanistic, and economic. Clinical outcomes can be either short term (e.g., improvement in glycemic control) or long term (e.g., reduction of diabetic complications). Process outcomes (e.g., performance of specified tests at specified intervals) may be used as measures of preventive care. Humanistic outcomes include patient quality of life (QOL) and satisfaction with care. Patient satisfaction is especially important in a disease such as diabetes where active, continuous patient self-care is essential to achieving good clinical outcomes. Finally, economic outcomes may be difficult to measure. Measurement of cost savings requires both the cost of the program and the costs avoided that can be attributed to the program. Because of the difficulty in measuring the latter, cost-effectiveness outcomes (e.g., cost per emergency department visit avoided) are often the most feasible economic outcomes to measure.

\section{Outcomes reporting}

Outcomes reporting, on the surface a relatively simple process, involves several significant conceptual issues. The most obvious issue is that any numerical measures at the patient level require a defined population (i.e., a de- 
nominator). Given steady enrollment of new patients and some rate of drop out, there must be an estimate of the effective patient population during a given time period. A more difficult issue is the attribution of outcomes. If the program is closely integrated with a primary care network, it would be virtually impossible to differentiate the effects of physician care from the incremental clinical benefits attributable to the program. A third issue is risk or severity adjustment of the patient population. In the analysis reported here, stratification of the population by level of glycemic control at enrollment was necessary in order to interpret the outcomes. For valid comparison to external benchmarks, differences in patient populations must be taken into account. Finally, it is important to distinguish between ongoing management reporting and one-time research evaluations of the kind described in this study.

Management reporting requires identification of needed data elements and their sources (e.g., charts, claims, questionnaires), and systems to collect and process the data. Data elements required for ongoing program monitoring and reporting include the following: demographic, clinical, health services utilization, education received, process checkoffs, patient satisfaction, and disease-specific clinical markers. It is essential that, for all event data collected, dates are included.

\section{CONCLUSION}

Disease management is an information-intensive process, requiring information systems capability that goes well beyond the requirements of the individual patient chart. The level of investment required can be daunting, especially in a setting where the patient charts themselves, the primary source of clinical data elements, are not electronically accessible. The process of manual chart review used in the current study, while feasible for a one-time evaluation, is much too labor intensive for ongoing data collection. In addition, the chart review revealed great variability in data quality across the individual practices of over 100 primary care physicians. For process measures of clini- cal care, seemingly the easiest outcomes to document, the question when reviewing charts was whether a test or exam was not done, or done and not documented. Health services utilization (claims data), while not collected in the current pilot study, would be a valuable component of a full-featured disease management program. Disease management also requires ongoing collection of self-reported patient data (QOL, satisfaction). The question then becomes whether the requirements of disease management are best served by dedicated information systems running in parallel to existing clinical and administrative systems, or by management reporting software fed by data extracts from existing databases. It is likely that health care suppliers will develop products along both lines with the state of existing infrastructure and the funds budgeted determining the choice of disease management system.

The data presented here suggest that a relatively inexpensive and easy-to-implement diabetes disease management program, centered on patient education in self-management, can achieve clinically significant improvements in glycemic control for a specific period of time $(6$ months), and result in a high level of patient satisfaction. In addition to issues of data management, this study illustrates that the degree of physician integration is one of the most salient features of a disease management program. A centralized program that is more integrated with individual physician practices and focused on provider education would presumably produce even better results, but at a significantly higher cost. Measuring the cost effectiveness of disease management programs is one of the most pressing areas for further research. Studies of the long-term effects of diabetes disease management programs are particularly needed in order to demonstrate both short- and long-term value to health care providers and organizations.

\section{ACKNOWLEDGMENTS}

We wish to thank Karen Maskin for her assistance with data analysis. This study was funded by a grant from Abbott Laboratories. 


\section{REFERENCES}

1. National diabetes fact sheet. Washington, DC: U.S. Department of Health and Human Services/Centers for Disease Control and Prevention, 1998.

2. American Diabetes Association. Clinical practice recommendations 2001. Diabetes Care 2001;24:suppl 1.

3. Weiner JP, Parente ST, Garnick DW, et al. Variation in office-based quality: a claims-based profile of care provided to Medicare patients with diabetes. JAMA 1995;273:1503-1508.

4. Diabetes Control and Complications Trial Research Group. The effect of intensive insulin treatment of diabetes on the development and progression of longterm complications in insulin-dependent diabetes mellitus. N Engl J Med 1993;329:977-986.

5. Testa MA, Simonson DC. Health economic benefits and quality of life during improved glycemic control in patients with type 2 diabetes mellitus: a randomized, controlled, double-blind trial. JAMA 1998;280: 1490-1496.

6. Aubert RE, Herman WH, Waters J, et al. Nurse case management to improve glycemic control in diabetic patients in a health maintenance organization: a randomized controlled trial. Ann Intern Med 1998;129: 605-612.

7. O'Connor PJ, Rush WA, Peterson J, et al. Continuous quality improvement can improve glycemic control for HMO patients with diabetes. Arch Fam Med 1996;5:502-506.

8. McCulloch DK, Price MJ, Hindmarsh M, et al. Improvement in diabetes care using an integrated population-based approach in a primary care setting. Disease Management 2000;3:75-82.

9. Sperl-Hillen J, O'Connor PJ, Carlson RR, et al. Improving diabetes care in a large health care system: an enhanced primary care approach. Jt Comm J Qual Improv 2000;26:615-622.

10. Zitter M. A new paradigm in health care delivery: disease management. In: Disease management: a systems approach to improving patient outcomes. American Hospital Publishing, 1997.

11. Kozma CM, Reeder CE, Schulz RM. Economic, clinical, and humanistic outcomes: a planning model for pharmacoeconomic research. Clin Ther 1993;6: 1121-1132.

Address reprint requests to: Michael Toscani, Pharm.D. HealthAnswers, Inc. 112 Titus Mill Rd. Pennington, NJ 08534

E-mail: Michael.Toscani@healthanswersinc.com 